\title{
Comparative whole genome re-sequencing analysis in upland New Rice for Africa: insights into the breeding history and respective genome compositions
}

Naoki Yamamoto ${ }^{1 *}$ D, Richard Garcia ${ }^{1}$, Tomohiro Suzuki ${ }^{2}$, Celymar Angela Solis ${ }^{1}$, Yuichi Tada ${ }^{3}$, Ramaiah Venuprasad ${ }^{4}$ and Ajay Kohli ${ }^{{ }^{*}}$

\begin{abstract}
Background: Increasing rice demand is one of the consequences of the steadily improving socio-economic status of the African countries. New Rice for Africa (NERICA), which are interspecific hybrids between Asian and African rice varieties, are one of successful breeding products utilizing biodiversity across the two different rice crop species. Upland NERICA varieties (NU) exhibit agronomic traits of value for the harsh eco-geography, including shorter duration, higher yield and stress tolerance, compared to local African varieties. However, the molecular basis of the traits in NU varieties is largely unknown.

Results: Whole genome re-sequencing was performed of four NU lines (3, 4, 5, and 7) and for the parental Oryza sativa WAB56-104 and Oryza glaberrima CG14. The k-mer analysis predicted large genomes for the four NU lines, most likely inherited from WAB56-104. Approximately 3.1, 0.10, and 0.40 million single nucleotide polymorphisms, multi nucleotide polymorphisms, and short insertions/deletions were mined between the parental lines, respectively. Integrated analysis with another four NU lines (1,2,8, and 9) showed that the ratios of the donor CG14 allelic sites in the NU lines ranged from 1.3 to $9.8 \%$. High resolution graphical genotype indicated genome-level similarities and common genetic events during the breeding process: five xyloglucan fucosyltransferase from O. glaberrima were introgressed in common. Segregation of genic segments revealed potential causal genes for some agronomic traits including grain shattering, awnness, susceptibility to bacterial leaf bright, and salt tolerance. Analysis of unmapped sequences against the reference cultivar Nipponbare indicated existence of unique genes for pathogen and abiotic stress resistance in the $\mathrm{NU}$ varieties.
\end{abstract}

Conclusions: The results provide understanding of NU genomes for rice improvement for Africa reinforcing local capacity for food security and insights into molecular events in breeding of interspecific hybrid crops.

Keywords: Genome structure, Oryza glaberrima, Rice, Polymorphism, Upland NERICA, WAB56-104

\footnotetext{
* Correspondence: n.yamamoto@irri.org; a.kohli@irri.org

${ }^{1}$ International Rice Research Institute, Los Baños, Laguna, Philippines

Full list of author information is available at the end of the article
} 


\section{Background}

Changing socio-economic conditions are driving the progressively increasing consumption of rice in the African countries. Hence, African countries have imported more than 10 million tons of rice annually in recent years (FAO 2013a). Besides, there is a sustained effort to supplement the imports with local rice cultivation in Africa. Namely, yield increase and harvested area expansion both were achieved to pull up the total rice production in Africa since 2000 (FAO 2013b). To further facilitate those, the improvement of the locally suited rice varieties is an important aspect in rice breeding.

Upland rice production is feasible with labor-saving management and can be a source of food and income in Africa. To integrate rice cultivation in poverty and hunger reduction, upland farmers should be able to grow rice. The development of the first generation upland NERICA (NU) varieties by the West Africa Rice Development Association (WARDA: at present the Africa Rice Center) in the 1990s was an important step in that direction. NU varieties are the products of surmounting above the reproductive barriers between Asian rice Oryza sativa and African rice Oryza glaberrima Steud. (Sano 1990). One of the first subsets of NU varieties (NU 1 to 11), derived from an upland tropical japonica cultivar WAB56-104, developed by WARDA as the recurrent parent, and the O. glaberrima accession CG14 as the donor parent, were released in 2000s (Sié et al. 2012). These NUs were adapted into the upland rice ecosystems in West African countries, exhibiting good yield potential (4-5 t/ha), short duration, no grain shattering and tolerance to lodging (Africa Rice Center 2008; Somado et al. 2008). Moreover, the NU varieties exhibit superior tolerance of biotic and abiotic stress factors such as rice yellow mottle virus (Attere and Fatokun 1983; Albar et al. 2003; Paul et al. 2003), rice blast (Somado et al. 2008), stem borders (Rodenburg et al., 2015), soil acidity (Somado et al. 2008), and soil salinity (Awala et al. 2010). Arguably, the NU rice grains exhibit high protein content $(\sim 10 \%)$ which makes for better nutritious value for the African consumers (Somado et al. 2008).

The NU varieties would be useful not only as maternal lines in rice breeding but also intermediary breeding materials that can transfer genes underlying useful agronomic traits from the parental lines into other varieties. The donor species O. glaberrima has attracted attention as a source of biotic and abiotic stress tolerance genes: i.e. genes for bacterial leaf blight, cyst nematode, iron toxicity, drought and weed competitiveness (Sano et al. 1984; Jones et al. 1997; Lorieux et al. 2003; Haefele et al. 2004; Singh et al. 2004; Sarla and Swamy 2005; Majerus et al. 2007; Vikal et al. 2007). In addition, the recurrent $O$. sativa parents seem to have useful genes for African rice breeding because those were selected from hundred lines under the local climate (Jones et al. 1997). Traore et al. (2011) reported that WAB56-104 showed long grain phenotype $(\sim 7.7 \mathrm{~mm})$, low amylase content, and relatively short duration. Recently, a draft genome sequence of the donor parent of O. glaberrima accession CG14 was reported (Wang et al. 2014), however, there is a lack of genetic information on $\mathrm{NU}$ and the recurrent parental varieties.

Understanding on genome architecture of the NU varieties would promote their appropriate and informed utilization in rice breeding for African countries. However, it is rather vague if deciphered from the existing genomic profiles. Genotyping by the limited number of DNA markers provided evidence for macro-level similarity among NU genomes and also some non-parental alleles (Semagn et al. 2007; Fukuta et al. 2012; Pariasca-Tanaka et al. 2015). Recently, four NU varieties (1, 2, 8 and 9) were sequenced at 10 to $15 \mathrm{X}$ depth as a part of the rice 3000 genome project (Li et al. 2014; Alexandrov et al. 2015). An indepth analysis of their genome sequences remains to be achieved.

In the present study, we conducted comparative resequencing analysis of the NU genomes using the Illumina high-throughput sequencing technique. We resequenced the genomes of four additional NU varieties $(3,4,5$, and 7$)$ as well as of the two parental lines. Genome size and homozygosity were examined by $k$-mer analysis of the sequencing data. We then performed an integrated sequence analysis of all eight NU varieties for single nucleotide polymorphisms (SNPs), multi nucleotide polymorphisms (MNPs) and short insertion and deletions (InDels). Application of the whole genome polymorphisms allowed prediction and characterization of the NU genome structures at high resolution. Enrichment of Gene Ontology on common and variety/ lineage-specific introgression segments from CG14 was tested for biased gene distributions. Analysis of chromosomal segment patterns identified gene candidates that are associated with phenotype. Gene information from WAB56-104 unmapped sequences, which were not mapped on the Nipponbare genome sequence properly, were analyzed and integrated with the four NU varieties sequenced in this study.

\section{Methods}

\section{Whole genome sequencing}

Rice seeds were distributed from Africa Rice Center (Côte d'Ivoire). Genomic DNA was prepared from etiolated seedlings cultured in the half strength of Murashige \& Skoog liquid medium (Murashige and Skoog 1962). DNA extraction was performed using the method described by Doyle (1987) with a few modifications. Integrity of DNA was analyzed by electrophoresis in $2 \%$ agarose, and DNA samples were subjected to high-throughput 
sequencing by Illumina HiSeq 4000 in Macrogen Inc. (Seoul, Korea). In the sequencing analysis, DNA library was constructed from fragmented genomic DNA (ranging from approx. 0.2 to $10 \mathrm{~kb}$ ) using TruSeq DNA PCR-FREE (350 bp) (Illumina), and $101 \mathrm{bp}$ paired-end short reads were generated in fastq format. The obtained raw data were processed by the Trimmomatic software version 0.33 (Bolger et al. 2014) with the options of 'LEADING:15, TRAINLING:15, SLIDINGWINDOW:4:15, MINLEN:20' to trim adapter and low-quality sequences. The raw sequencing data were deposited to DDBJ Sequencing Read Archive (accession number: DRA006795).

\section{k-mer analysis}

The pre-processed high quality reads were applied to count $k$-mers by the software KMC 2 version 2.3.0 (Deorowicz et al. 2015). Genome size prediction was carried out using the software GCE version 1.0.0, which utilizes a Bayes model based method (Liu et al. 2013). Reference data were downloaded from NCBI Sequencing Read Archive for cv. Nipponbare (SRR545231, SRX179262, DRR028131, DRR028132, DRR083658, and SRR1043564), IR64 (SRR3098100), and Moroberekan (DRR003661).

\section{Flow cytometry analysis}

Genome DNA contents $(\mathrm{pg} / 2 \mathrm{C})$ were determined by a flow cytometry analyzer EC800 (Sony Biotechnology Inc., CA, USA). Nuclei of samples were prepared as follows: 1) fresh leaves were chopped into finely minced tissues using a razor blade and mixed with $600 \mu \mathrm{l}$ of extraction buffer [50 mM Tris- $\mathrm{HCl}$ ( $\mathrm{pH} 7.5$ ), $0.5 \%$ polyvinypyrrolidoneK90, $0.01 \%$ Triton X-100, and $0.63 \% \mathrm{Na}_{2} \mathrm{SO}_{4}$ ] at room temperature, 2) the supernatant was filtered via a single layer of nylon mesh with $25 \mu \mathrm{m}$ pore size (NYTAL P-25, SEFAR AG, Ruschlikon, Switzaland), 3) the filtrate was subjected to RNase treatment and staining by propidium iodide (PI) with $3 \mu \mathrm{l}$ of RNase A $(10 \mathrm{mg} / \mathrm{ml})$ and $6 \mu \mathrm{l}$ of Propidium Iodide (PI) Solution $(0.5 \mathrm{mg} / \mathrm{ml}$, Sony Biotechnology) for $30 \mathrm{~min}$ at room temperature under dark. Signals of PI-stained nuclei were obtained by the flow cytometer with a band pass filter which transmits $570 \sim 620 \mathrm{~nm}$ excitation of PI at $40 \mu \mathrm{l} / \mathrm{min}$ of flow rate. At least 1000 nuclei were analyzed per measurement. Peak areas of given signals were used for calculation of DNA contents. Each measurement was with technical duplicates and four biological replicates. A linear standard curve was made based on Arabidopsis thaliana (Col-0), Brachypodium distachyon (L.) Beauv., Solanum lycopersicum (cultivar Micro-Tom), and Zea mays (cultivar Peter corn). DNA contents of these samples were defined as $0.32,0.70,2.0,5.3 \mathrm{pg} / 2 \mathrm{C}$, respectively, based on prior knowledge (Arumuganathan and Earle 1991; Bennett et al. 2003; Bennett and Leitch 2005). Determined DNA contents were converted into haploid genome size using the conversion factor of $1 \mathrm{pg}$ DNA $=978$ million base pairs (Doležel et al. 2003). The rice reference cultivar Nipponbare was analyzed as a control for the African varieties.

\section{Bioinformatics pipeline for polymorphism mining}

In order to mine polymorphism candidates, we prepared a bioinformatics pipeline. Processed sequence reads were mapped against the rice genome (16 pseudomolecules of cultivar Nipponbare, chromosome (Chr) 1 to 12, ChrUn, ChrSy, plastid, and mitochondrial genome contigs of MSU 7.0: http://rice.plantbiology.msu.edu/) by BurrowsWheeler Aligner MEM (Li and Durbin 2009) ver. 0.7.12 with option of '-O 4'. This mapping condition was determined after comparisons under conditions with different gap penalty in a small batch pre-analysis. Utilization of the full set of pseudomolecules made it possible to reduce mismapping between homologous loci between pseudomolecules. Generated mapping data file (SAM file) was processed for filtering out discordant paired reads using in-house Perl scripts. Filtered SAM file was converted into a BAM file and sorted by SAMtools ver. 0.1.19 (Li et al. 2009). Sorted BAM files of 10 genotypes were co-realigned by the Genome Analysis Tool Kit ver. 3.5 (McKenna et al. 2010). Resultant mapping data were converted into a pileup format file by SAMtools with the command 'mpileup' with '-Q 0' option. Sequence variants between the parental lines and NERICA to either parental line were called if the read depth was no less than 20 for WAB 56-104, CG 14, and NERICA 7, 25 for NERICA 5, 21 for NERICA 4, 6 for NERICA 9, 5 for NERICA 1, 18 for NERICA 3, 4 for NERICA 2 and NERICA 8 and coincidence within genotype was no less than $80 \%$ for homozygous polymorphism mining. SNPs and MNPs were called using an in-house Perl script 'SNiPer2'. Short Indel sites were called using the software VarScan2 version 2.3.9 with the command of somatic and the options of '-min-base-qual 0 '.

\section{Cleaved amplified polymorphic sequences (CAPS) assay} Genomic DNA surrounding SNP candidates were amplified by PCR using KAPA3G Plant PCR Kit (KapaBiosystems, Inc.). PCR products were digested by a restriction enzyme and electrophoresed in agarose gel with presence of FastStart SYBR Green Master (Roche Diagnostics $\mathrm{GmbH}$ ) at $100 \mathrm{~V}$ for $60 \mathrm{~min}$. Gels were imaged using a Molecular Imager Gel Dox XR System (Bio-Rad Laboratories, Inc.).

\section{Survey for structural variations}

A structural variant detection tool Manta version 1.1.1 (Chen et al. 2016) was employed for calling translocation breakends, inversions, tandem repeats, long insertions and long deletions with the default condition. Raw data 
files (VCF format) were converted into the BEDPE format using SVtools (https://github.com/ctsa/svtools) for analysis. Potential structural variants after QC filtering were selected. Copy number variations $(\mathrm{CNVs})$ were searched using CNVnator version 0.3.3 (Abyzov et al. 2011).

\section{Prediction of chromosomal segment type}

All the SNPs, MNPs, and short InDel sites were aligned into a data matrix. Potential de novo mutation sites, which showed the same allele between the parental varieties but a different common allele in NU varieties, were excluded for reducing artifacts. Genetic imputation was carried out to infer chromosomal segments derived from WAB56-104, CG14, or non-parental varieties.

\section{Gene set enrichment analysis}

Gene Ontology enrichment was examined by the agriGO2 web tool (Tian et al. 2017). 'Singular Enrichment Analysis' was applied with the default parameters. Statistical analysis options of hypergeometric test with multi test adjustment method of Holm were selected.

\section{De novo assembly}

Full-length of unmapped paired end reads of WAB56-104 were collected and probable contaminant sequences were excluded based on results of BLASTN against human, $E$. coli and yeast genomic sequences (98\% identity of $101 \mathrm{bp}$ ). Resultant paired-end reads were applied to de novo assembly using SOAPdenovo2 version 2.40 (Luo et al. 2012) with different $k$-mer from 21 to 81 . The assembly result with the longest N50 length was obtained with $k$-mer of 67. Then, series of ambiguous sequence ' $N$ ' of the genomic scaffolds were filled using the software the GapCloser module version 1.12 (Luo et al. 2012).

\section{Gene prediction and annotation}

Repeat sequences on genome scaffolds were masked using RepeatMasker version open-4.0.6 with rmblastn version 2.6.0, RepBase Update 20,160,829 and RM database version 20,160,829. Then, structural gene annotations were given using Augustus web interface (http:// bioinf.uni-greifswald.de/augustus/submission.php; Keller et al. 2011). Predicted protein sequences were annotated based on BLAST searches (Blast+ version 2.4.0) against the manually annotated protein database Swiss-Prot (Boeckmann et al. 2005), all proteins in rice (MSU7), in Arabidopsis (TAIR10, Lamesch et al., 2012), in maize (maizeGDB AGPv4, Andorf et al. 2015), in Sorghum bicolor (PlantGDB the number 79, Duvick et al. 2008), and in Brachypodium (PlantGDB the number 192). GO terms were assigned using BLAST2GO version 4.1.9 (Conesa and Götz 2008).

\section{Mapping of unmapped short reads}

Unmapped paired end reads were collected and mapped upon the genomic scaffolds of unmapped sequences from WAB56-104 using BWA mem with the default condition. After filtering out discordant and multimapped paired reads using in-house Perl scripts, averaged read depth on each gene transcribed region was calculated in each genotype.

\section{Results and discussion \\ Whole genome re-sequencing}

Re-sequencing data for NU3, 4, 5, and 7, and for WAB56-104 and CG14 were obtained at 32.5-53.8X coverage. In total 1.48 billion short reads with the length of $101 \mathrm{bp}$ were generated (Additional file 1: Table S1). Analysis of the sequence reads revealed $k$-mer distributions suggesting homozygosity of the sequenced genomes (Additional file 2: Figure S1); a small peak ( $k$-mer depth $=16$ ) was observed in NERICA 5, and it could be contaminants in the sequencing steps. Genome sizes were predicted using the $k$-mer distributions; CG14 genome exhibited the smallest size of $399.8 \mathrm{Mbp}$, WAB56-104, NU3 and NU7 exhibited larger sizes ranging from 444.9 to $455.4 \mathrm{Mbp}$, and NU4 and NU5 genome sizes were intermediate between the parental lines (Table 1). To evaluate the reliability of those predictions, we analyzed publicly available sequencing data in cv. Nipponbare (temperate japonica), IR64 (indica), and an African variety Moroberekan (tropical japonica). The result of Nipponbare ranged from 371.1 to $421.3 \mathrm{Mbp}$, which was close to the actual genome size of 384.2 to $386.5 \mathrm{Mbp}$ (Kawahara et al. 2013). The result of IR64 (355.6 Mbp) was smaller than that of Nipponbare, being consistent with the sizes of genome assemblies in both cultivars (Schatz et al. 2014). The result of Moroberekan was $446.8 \mathrm{Mbp}$, which was nearly identical to that of WAB56-104. These data supported the size diversity and the larger genome sizes of NU varieties and the parental variety compared to the Nipponbare genome.

It was notable that all the six varieties we sequenced exhibited larger genome sizes compared to Nipponbare. There are still controversial hypotheses on the origin of differences in genome size in different $O$. sativa genotypes. Burr (2002) reviewed the predicted size ranged from 403 to $430 \mathrm{Mbp}$, while Kawahara et al. (2013) mentioned the actual size of the sequenced Nipponbare genome was between 384.2 and $386.5 \mathrm{Mbp}$. Miyabayashi et al. (2007) observed that the DNA content of a wild rice Oryza glumaepatula, which has the AA genome, was 15 . $4 \%$ higher than that of the Nipponbare genome. To evaluate our $k$-mer-based estimation, nuclear DNA contents of the African varieties were determined by measuring PI-stained nuclei using flow cytometry. The estimated genome size by this way ranged from 392. 
Table 1 Prediction of genome size and sequencing depth

\begin{tabular}{|c|c|c|c|c|}
\hline \multirow[t]{2}{*}{ Variety } & \multicolumn{2}{|l|}{ k-mer analysis } & \multicolumn{2}{|l|}{ Flow cytometry } \\
\hline & Genome size (Mb) & Sequencing depth $(X)$ & DNA content $(\mathrm{pg} / 2 \mathrm{C})$ & Genome size (Mb) \\
\hline WAB 56-104 & 446.982 & 38.9 & $0.896 \pm 0.016$ & $438.27 \pm 7.86$ \\
\hline CG 14 & 399.771 & 43.7 & $0.802 \pm 0.006$ & $392.06 \pm 2.83$ \\
\hline NERICA 3 & 444.887 & 32.5 & $0.849 \pm 0.016$ & $415.16 \pm 7.65$ \\
\hline NERICA 4 & 425.708 & 45.5 & $0.878 \pm 0.012$ & $429.46 \pm 5.91$ \\
\hline NERICA 5 & 424.061 & 53.8 & $0.845 \pm 0.019$ & $412.96 \pm 9.48$ \\
\hline NERICA 7 & 455.363 & 37.8 & $0.914 \pm 0.024$ & $446.70 \pm 11.87$ \\
\hline Nipponbare & $371.142-421.300$ & - & $0.863 \pm 0.014$ & $421.76 \pm 6.71$ \\
\hline IR64 & 355.615 & - & - & - \\
\hline Moroberekan & 446.806 & - & - & - \\
\hline
\end{tabular}

k-mer was set as "17"

$1 \mathrm{Mb}$ of CG14 to $446.7 \mathrm{Mb}$ of NU7 (Table 1). The genome size of Nipponbare $(421.8 \mathrm{Mb})$ was larger than those of the latest genome assembly, but it was close to the range given from the $k$-mer analysis. The DNA content of Nipponbare was smaller than those of NU7 and WAB 56-104 with statistical significance (Student's $t$ test, at $10 \%$ level) and larger than that of CG14 with statistical significance (Student's $t$-test, at 1\% level). A smaller genome size of $O$. glaberrima than those of $O$. sativa was previously reported by Martínez et al. (1994) and Uozu et al. (1997). Remaining three varieties did not show any clear difference although their values were numerically different from that of Nipponbare. Taken together, one common observation which was not inconsistent with previous studies was that the recurrent parent WAB 56-104 had a larger genome than Nipponbare, and it is likely to be inherited in NU7. If our relative estimation of WAB56-104 and Nipponbare genome size is trustable, the WAB56-104 genome could have unique genetic information that was not found on the Nipponbare genome assembly. We examined this possibility by de novo assembly of unmapped sequence reads later (section "Unmapped sequences from WAB56-104").

\section{Genomic comparison in the parental varieties}

Parental SNPs, MNPs, and short InDels were mined using a bioinformatics pipeline. To consider genome sequence diversity between $O$. sativa and O. glaberrima (Wang et al. 2014), we set the mapping parameters after optimization. Against the Nipponbare reference genome, 3,088,818 SNPs, 103,568 MNPs, and 404,070 potential InDels were found (Table 2). Approx. $87.8 \%$ and $11.9 \%$ of the parental SNPs represented common nucleotide alleles between Nipponbare and WAB56-104 and Nipponbare and CG14, respectively. The MNPs were comprised of four categories: di, tri, tetra, and pentanucleotide polymorphisms, and di-MNPs were the most abundant (97.0\%; Additional file 3: Table S2). Majority
(81.8\%) of the MNPs represented the same nucleotide types as Nipponbare, but $6.2 \%$ were of CG14. For the short InDels, the length ranged from 1 to $45 \mathrm{bp}$, and $90 \%$ of these were 1-4 bp length (Additional file 4: Table S3). Most of the InDels (90.9\%) were detected as changes in CG14 compared to the alleles of WAB56-104 and Nipponbare. These results are consistent with the knowledge that tropical japonica rice is genetically closer to temperate japonica than to O. glaberrima. More distant genetic relationship of WAB56-104 to O. glaberrima accessions was observed to Nipponbare (Semon et al. 2005). However, the actual similarity between Nipponbare and CG14 at polymorphic sites might be closer because a technical bias would exist when the sequence reads of the parental lines were aligned upon the Nipponbare genome sequence. Total of 42 polymorphic sites across all the chromosomes were tested by CAPS assays, and 40 of them were validated (Additional file 5: Table S4), suggesting more than $95 \%$ of mined polymorphisms in this study are genuine.

Hundred sites of structural variation between $O$. sativa and O. glaberrima were reported previously (Hurwitz et al. 2010). We searched potential structural variants, translocation breakends, inversions, tandem repeats and long InDels between WAB56-104 and CG14 in silico. By the reciprocal somatic calls, we predicted 8661 of translocation breakends, 329 of inversions, 320 of tandem duplications, and 4715 of long InDels (Table 3). The structrural variants were distributed across all the chromosomes (data not shown). The average length of structural variants was as follows: $1.5 \mathrm{Mbp}$ for inversion, 59.4 $\mathrm{kbp}$ for tandem duplication, $101.3 \mathrm{kbp}$ for long deletion, $1.7 \mathrm{kbp}$ for long insertion. We also searched structural variations between Nipponbare and the two parental varieties separately. This computation revealed numerous structrual variants potentially existed between Nipponbare and the two parental varieties (Table 3). Number of structural variants in WAB56-104 ranged 
Table 2 Polymorphic sites between WAB 56-104 and CG 14

\begin{tabular}{|c|c|c|c|c|c|c|c|}
\hline \multirow[t]{2}{*}{ Chr } & \multicolumn{2}{|c|}{ Nucleotide polymorphism } & \multicolumn{2}{|l|}{ Insertion } & \multicolumn{2}{|l|}{ Deletion } & \multirow[t]{2}{*}{ Total } \\
\hline & SNP & MNP & WAB56-104 & CG 14 & WAB56-104 & CG 14 & \\
\hline 1 & 360,381 & 11,386 & 1972 & 20,132 & 2804 & 24,478 & 49,386 \\
\hline 2 & 316,206 & 10,336 & 1564 & 17,498 & 2320 & 21,101 & 42,483 \\
\hline 3 & 306,733 & 9299 & 1293 & 16,964 & 1879 & 20,338 & 40,474 \\
\hline 4 & 270,022 & 9601 & 1370 & 14,362 & 2061 & 17,316 & 35,109 \\
\hline 5 & 251,323 & 8021 & 1377 & 13,075 & 2055 & 15,560 & 32,067 \\
\hline 6 & 271,081 & 9447 & 1413 & 14,354 & 1997 & 17,557 & 35,321 \\
\hline 7 & 254,203 & 8756 & 899 & 14,537 & 1314 & 17,184 & 33,934 \\
\hline 8 & 221,116 & 7317 & 1131 & 11,605 & 1632 & 14,365 & 28,733 \\
\hline 9 & 190,775 & 6350 & 666 & 10,347 & 893 & 12,284 & 24,190 \\
\hline 10 & 201,301 & 7146 & 1771 & 9125 & 2600 & 11,457 & 24,953 \\
\hline 11 & 238,964 & 8611 & 1884 & 11,917 & 2360 & 14,295 & 30,456 \\
\hline 12 & 203,812 & 7230 & 1527 & 10,421 & 2084 & 12,631 & 26,663 \\
\hline Un & 538 & 9 & 3 & 20 & 5 & 32 & 60 \\
\hline Sy & 2363 & 59 & 7 & 113 & 2 & 119 & 241 \\
\hline Total & $3,088,818$ & 103,568 & 16,877 & 164,470 & 24,006 & 198,717 & 404,070 \\
\hline
\end{tabular}

from $32.9 \%$ (long insertion) to $48.7 \%$ (tandem duplication) of those in CG14. Average length of inversions and tandem duplications in CG14 (1.54 Mbp and $65.5 \mathrm{kbp}$, respectively) was close to those in WAB56-104 (1.35 Mbp and $55.2 \mathrm{kbp}$, respectively), while average length of long InDels in WAB56-104 (1.8 kbp and $7.0 \mathrm{kbp}$, respectively) was longer than those in CG14 (1.4 kbp and $5.9 \mathrm{kbp}$, respectively). This observation is due to much more InDels, which are of relatively shorter length, found in CG14. Experimental validation of those structural variations remains to be performed.

\section{Polymorphisms in NU varieties}

For polymorphisms among NU varieties, the new sequencing data of the four NU genomes 3, 4, 5 and 7 were used along with the publicly available sequences of the other four NU genomes 1, 2, 8, and 9 (Additional file 6: Table S5). Polymorphisms between each NERICA and both parents were called, and a total of 4,461,719 polymorphic sites were found for SNPs, MNPs and short InDels (Table 4). Population structure of the 10 varieties (8 NUs and 2 parents) was analyzed using common polymorphic sites (1,026,367 sites). Principal component analysis (PCA) was used to dissect variance of allelic divergence of the 10 genomes (Fig. 1). PC1, which explained $70.9 \%$ variance, represented a large part of the difference between the two parental genomes. PC2 and PC3, which explained $14.7 \%$ and $8.22 \%$ variance, respectively, represented differences among the NU varieties. NU3 was plotted at the same location as NU4, and at a different site NU8 and NU9 were plotted at the same location. This could most likely be due to NU3 being a sister line of NU4 and NU8 being a sister line of NU9.

The number of candidate polymorphisms discovered revealed that the NU varieties contained the donor alleles in different proportions, which ranged from 1.32 to $9.03 \%$ (Table 4). For example, NU5 exhibited the highest proportion of the CG14-specific SNPs (9.81\%). Comparatively lower proportions of the CG14-specific SNPs at 1.32 and $1.33 \%$ were noted in NU3 and NU4 respectively. These results reflected different amount of introgression segments from CG14. Frequency of the non-parental SNPs among the total SNPs ranged from

Table 3 Structural variants in the parental lines and Nipponbare

\begin{tabular}{lllllc}
\hline Comparison & $\begin{array}{l}\text { Interchromosomal } \\
\text { translocation breakend }\end{array}$ & Inversion & Tandem duplication ${ }^{* 2}$ & Long deletion $^{* 3}$ & Long insertion $^{* 3}$ \\
\hline WAB 56-104 vs. CG14 & 6807 & 283 & 244 & 3741 & 584 \\
CG14 vs. WAB56-104 & 1238 & 46 & 76 & 336 & 54 \\
Nippobare vs. WAB 56-104 & 3346 & 165 & 154 & 2222 & 282 \\
Nippobare vs. CG14 & 9176 & 381 & 316 & 6071 & 857 \\
\hline
\end{tabular}

*1 Inversion between $100 \mathrm{bp}$ to $10 \mathrm{Mbp}$

*2 Tandem duplication between $100 \mathrm{bp}$ to $1 \mathrm{Mbp}$

*3 Insertion and deletion between $50 \mathrm{bp}$ to $1 \mathrm{Mbp}$ 
Table 4 Number of polymorphisms in the upland NERICA

\begin{tabular}{|c|c|c|c|c|c|c|c|c|}
\hline \multirow[t]{2}{*}{ Genotype } & \multirow[t]{2}{*}{ Category } & \multicolumn{3}{|l|}{ Allele type } & \multicolumn{2}{|c|}{ CG 14 allele (\%) } & \multicolumn{2}{|c|}{ Non-parental allele (\%) } \\
\hline & & WAB56-104 & CG 14 & Non-parental & Category & All & Category & All \\
\hline \multirow[t]{3}{*}{ NERICA 1} & SNP & 2464390 & 247641 & 101458 & 8.80 & 9.03 & 3.61 & 3.81 \\
\hline & MNP & 79607 & 6336 & 8975 & 6.68 & & 9.46 & \\
\hline & Short InDel & 324348 & 43036 & 14852 & 11.26 & & 3.89 & \\
\hline \multirow[t]{3}{*}{ NERICA 2} & SNP & 1485308 & 148296 & 42301 & 8.85 & 8.68 & 2.52 & 2.65 \\
\hline & MNP & 46795 & 3990 & 3566 & 7.34 & & 6.56 & \\
\hline & Short InDel & 171010 & 14367 & 5123 & 7.54 & & 2.69 & \\
\hline \multirow[t]{3}{*}{ NERICA 3} & SNP & 2989656 & 41101 & 39623 & 1.34 & 1.32 & 1.29 & 1.39 \\
\hline & MNP & 98929 & 671 & 3991 & 0.65 & & 3.85 & \\
\hline & Short InDel & 333122 & 4601 & 5371 & 1.34 & & 1.57 & \\
\hline \multirow[t]{3}{*}{ NERICA 4} & SNP & 3008891 & 41574 & 40255 & 1.35 & 1.33 & 1.30 & 1.41 \\
\hline & MNP & 99336 & 681 & 4059 & 0.65 & & 3.90 & \\
\hline & Short InDel & 322610 & 4520 & 5457 & 1.36 & & 1.64 & \\
\hline \multirow[t]{3}{*}{ NERICA 5} & SNP & 2637694 & 293878 & 79951 & 9.76 & 9.81 & 2.65 & 2.91 \\
\hline & MNP & 85743 & 8884 & 7838 & 8.67 & & 7.65 & \\
\hline & Short InDel & 275398 & 34231 & 12349 & 10.63 & & 3.84 & \\
\hline \multirow[t]{3}{*}{ NERICA 7} & SNP & 2471034 & 117058 & 82482 & 4.38 & 4.32 & 3.09 & 3.36 \\
\hline & MNP & 74904 & 1816 & 8946 & 2.12 & & 10.44 & \\
\hline & Short InDel & 272139 & 12842 & 11127 & 4.34 & & 3.76 & \\
\hline \multirow[t]{3}{*}{ NERICA 8} & SNP & 1476391 & 98444 & 96093 & 5.89 & 5.82 & 5.75 & 6.05 \\
\hline & MNP & 46196 & 1787 & 8550 & 3.16 & & 15.12 & \\
\hline & Short InDel & 164605 & 11231 & 11142 & 6.01 & & 5.96 & \\
\hline \multirow[t]{3}{*}{ NERICA 9} & SNP & 1786210 & 120441 & 116935 & 5.95 & 5.88 & 5.78 & 6.10 \\
\hline & MNP & 54940 & 2150 & 10599 & 3.18 & & 15.66 & \\
\hline & Short InDel & 203351 & 13928 & 14197 & 6.02 & & 6.13 & \\
\hline
\end{tabular}

1.39 to $6.10 \%$. These numbers were compatible with the frequency of non-parental loci of $2.2 \%$ obtained by SSR maker-mediated genotyping (Semagn et al. 2007). Non-parental allele polymorphisms were the most frequent in NU9 and the least frequent in NU3 and NU4 (Table 4). Notably, the rates of CG14 allele and nonparental allele were at the same level, which implied that mutations, chromosomal rearrangements, or perhaps out-crossing contributed to the diversity of the NU genomes.

\section{Chromosomal structure in NU varieties}

The unique breeding processes of NU varieties could bring genomic alterations in various ways: de novo mutations, chromosomal rearrangement, translocation, chromosomal loss, etc., which might be required for stabilization of hybrid genomes and adaptive evolution (Baack and Rieseberg 2007; Rieseberg and Willis 2007; Morales and Dujon 2012). The chromosomal structure of the NU varieties was inferred using genetic imputation, by considering all polymorphic sites to predict the recipient parent segments of WAB56-104, the introgression segments from CG14, and potential non-parental segments. For the proportion of CG14 segments among NU varieties a wide range of 1.40 in NU3 and 4 to $10.1 \%$ in NU2 was noted. Similarly, the potential non-parental segments ranged from 0.090 of NU3 and 4 to $2.74 \%$ of NU9. Graphical genotype revealed the chromosomal structures of the NU varieties (Fig. 2). Reiterating the result from PCA, NU2 and 5, NU3 and 4 and NU8 and 9 exhibited highly related genotypes, while NU2 and 5 revealed large differences in introgressions from CG14 on Chr 4 . NU1 and 5 exhibited similarities at limited regions for example at the periphery of the centromeric region on the Chr 2, 3, 7 and 11, the upper edge of Chr 6, 7, and 9, and the bottom edge of Chr 4 . These results suggested that the known NU varieties originated from a limited number of independent interspecific hybridization events but that sister lines were identified as independent events, adding to the number of apparently independent NU varieties. Frequent distribution of short 


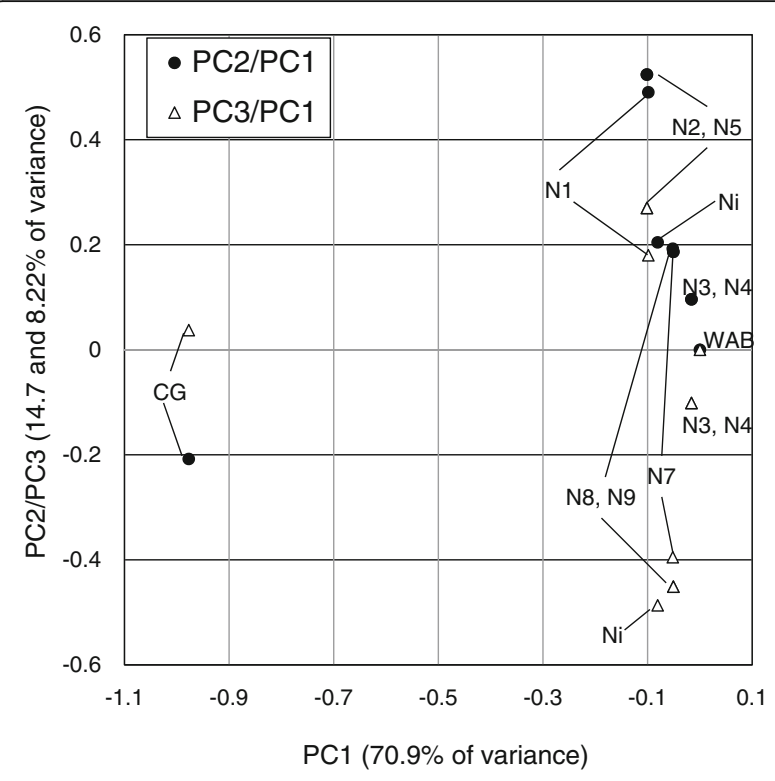

Fig. 1 PCA score plot for representing genotypic diversity. The X-axis represents $P C 1$ and the $Y$-axis shows $P C 2$ and PC3. Ni: Nipponbare, WAB: WAB56-104, CG: CG14, N1 to N9: NERICA 1 to NERICA 9

non-parental segments could be due to a combination of factors such as structural variants between Nipponbare and the parental lines, de novo mutations and genomic alterations at the chromosomal level. However, some large non-parental segments were observed. For example, in NU1 the middle part of Chr 8, which contained a fragrance gene $B A D H 2$ from WAB638-1 (Asante et al. 2010). Chr 1 in NU5 and Chr 7 in NU7 also indicated non-parental segments. In the previous genotyping by microsatellite markers (Semagn et al. 2007), those nonparental segments were not detected.

Common introgression segments from CG14 across the eight NU varieties totaled $637,849 \mathrm{bp}$, composed from 3168 segments. These were frequent in Chr 6 (1608 segments) and 10 (1143 segments) (Additional file 7: Table S6). Also, the common introgression segments were closely distributed (within 1.4 to $1.8 \mathrm{Mbp}$ ) on each of these two chromosomes. For example on Chr 6, they occurred from 5,613,148 to 7,010,047 and on Chr 10 from 174,587 to $1,974,978$. These fragmented segments might be due to structural variations between NERICA and Nipponbare/WAB56-104 or due to recombination between unlinked genes. The longest introgression segment was 24,125 bp on Chr $7(3,885,715-3,909,839)$, which was followed by 23,541 bp on Chr 10 (1,501,250$1,524,790)$. To examine gene composition on the common introgression segments from CG14, enrichment of GO terms were tested. It appeared that $11 \mathrm{GO}$ terms, including 'cell wall biogenesis' [GO:0042546] and 'transferase activity, transferring glycosyl groups' [GO:0016757], were over-represented. That enrichment was due to five xyloglucan fucosyltransferase genes that were located at the same locus (Chr 6: 5,701,639-5,734,237) (Additional file 8: Table S7). Although this enrichment alone did not look biologically informative, this locus was co-localized with quantitative trait loci (QTLs) of typical agronomic traits and grain quality between $O$. sativa and $O$. glaberrima (Lorieux et al. 2000; Aluko et al. 2004). The facts might imply that the locus containing the xyloglucan fucosyltransferase genes was positively acted on during the selection process for developing the NU varieties. Since the region of Chr6: 5,613,148 to 7,010,047 contains 207 genes in the Nipponbare genome, we could not specify genes relevant to the QTLs in this study.

Xyloglucan fucosyltransferase catalyzes transfer of Fucose (Fuc) from GDP-Fuc to a galactosyl residue of xyloglucan in the process of fucogalactoxyloglucan biosynthesis. Xyloglucan is a key component in cell walls and can play a role in cell wall structure and function. Recently, fucogalactoxyloglucan, which is widely distributed across dicot plants, was surprisingly detected in root hairs and anthers in rice (Liu et al. 2015), however, the biological function of fucogalactoxyloglucan is still unclear. The five xyloglucan fucosyltransferase genes were categorized into three groups based on their protein sequence similarities (Additional file 9: Figure S2). LOC_OsO6g10910 is a candidate fucosyltransferase coexpressed with a xyloglucan glycosyltransferase OsCSLC3 (Liu et al. 2015). LOC_OsO6g10920 was a probable ortholog of AtFUT3, of which overexpression altered cell wall composition and detrimental (Sarría et al. 2001). We observed several CG14-alleles that were introgressed into NU varieties caused amino acid substitutions in these genes (Additional file 10: Figure S3). Many CG14-alleles were also observed in the promoter regions. Cell wall in plants is the primary component that can determine the physical properties and protects them from against biotic and $a$ biotic stress (Zabotina 2012). These genes from CG14 might affect on agronomic characteristics in the upland $\mathrm{NU}$ varieties.

Variety-specific/lineage-specific introgression segments were also predicted in all the $\mathrm{NU}$ varieties (Additional file 11: Table S8). The total nucleotide ranged from $81.9 \mathrm{kbp}$ in NU4 to $6.85 \mathrm{Mbp}$ in NU8 and 9 lineage. Number of genes with the segments varied from 218 in NU4 to 4906 in NU8 and 9 lineage. Various kinds of genes that would be from CG14 were found (Additional file 12: Table S9). Gene Ontology enrichment analysis (GOEA) indicated 109 overrepresented GO terms, implying biased distribution of particular genes in NU1, 2, 5, 7 and the two lineage of NU2 and NU5, and NU8 and NU 9 (Additional file 13: Table S10). The listed GO categories might relate to their variety-specific characteristics, however, the biological meaning remains to be examined. 


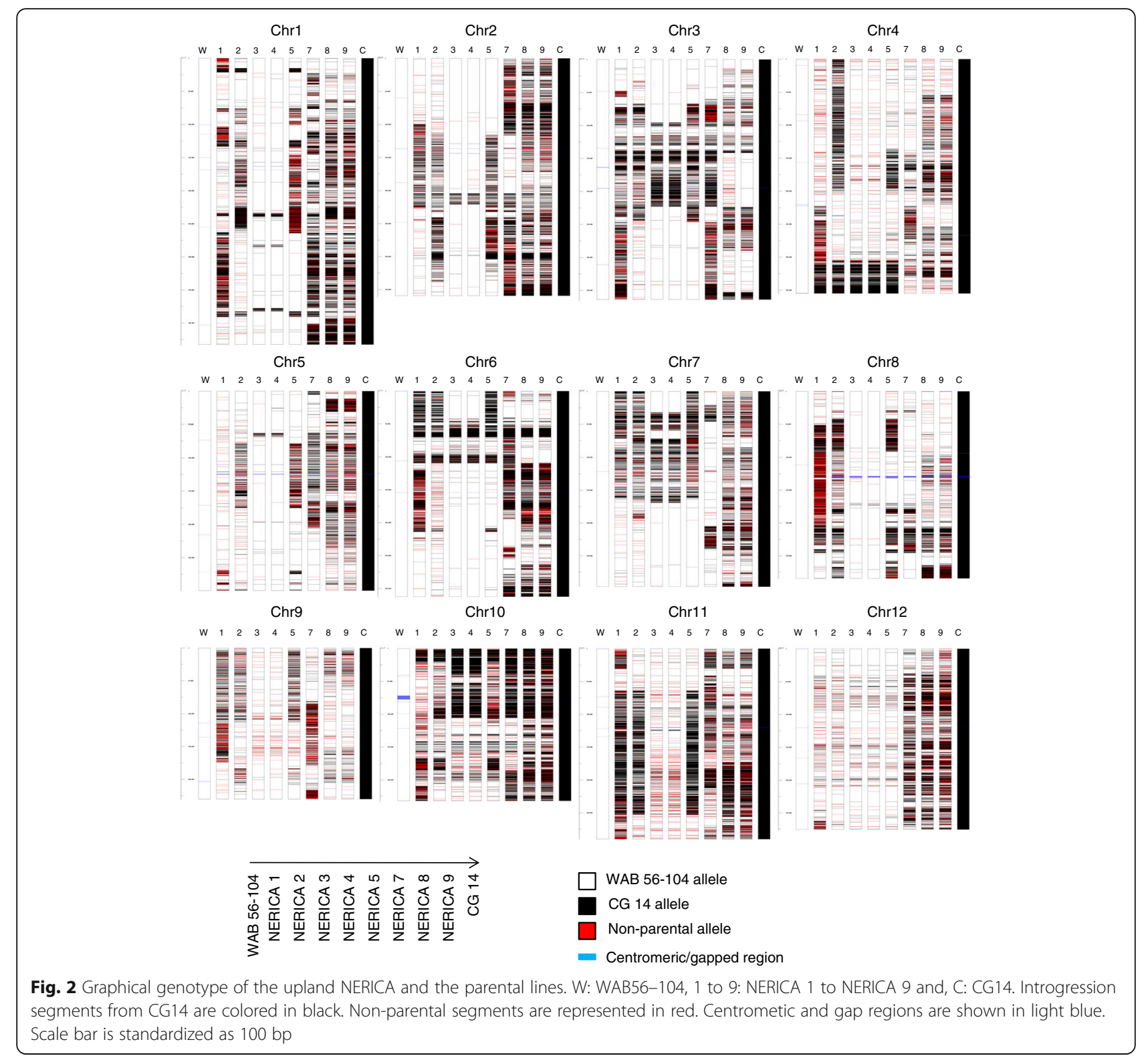

\section{Gene composition relevant to traits}

Grain shattering habit is the major constraint in $O$. glaberrima rice production (Africa Rice Center 2008). In agreement with disappearance of this trait in the NU varieties, key genes for grain shattering, SHATTERING 3/SEED SHATTERING 4 (LOC_Os04g57530, Li et al. 2006), qSH1 (LOC_Os01g62920, Konishi et al. 2006), and SHAT1 (LOC_Os04g55560, Zhou et al. 2012), were on chromosomal segments of WAB56-104 (Fig. 3). In the case of SHATTERING 3, five of non-synonymous parental polymorphisms were on the coding region, and one of the polymorphisms was the identical allele associated with shattering habits (Asp for non-shattering, Lys for shattering) (Fix. 3a). The causal allele of $q S H 1$ was not polymorphic among the African varieties, however, one non-synonymous SNP was found in CG14 (Fix. 3b). This SNP locates on the homeobox $\mathrm{KN}$ domain [PF05920] and substitutes Thr of WAB 56-104 into Pro of CG14. The structural and biochemical properties of the two amino acids might affect the function of the qSH1 gene. SHAT1 exhibited a mixed allelic pattern in the genic region while the probable promoter region of NU varieties consistently showed only of WAB 56-104 alleles (Fig. 3c). The corresponding CG14 segments, which are responsible for shattering, would be excluded in the processes of backcrossing followed by the artificial selection.

Discovery of trait-associated alleles helps in elucidating the genetic reasons underlying target trait variation. The high-resolution graphical genotype is useful to check 


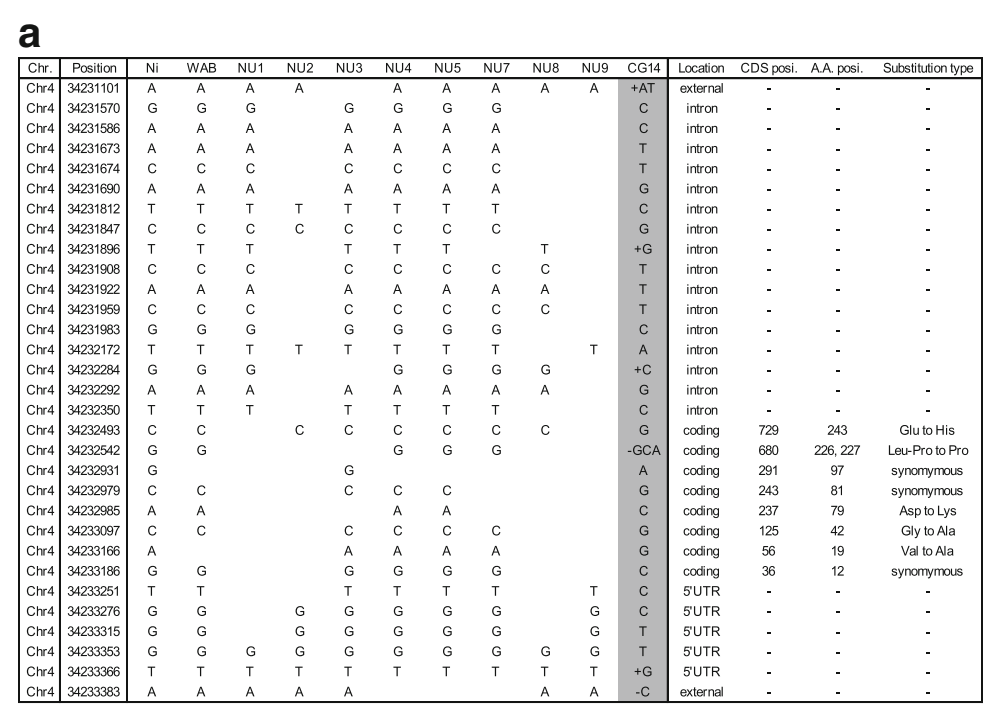

b

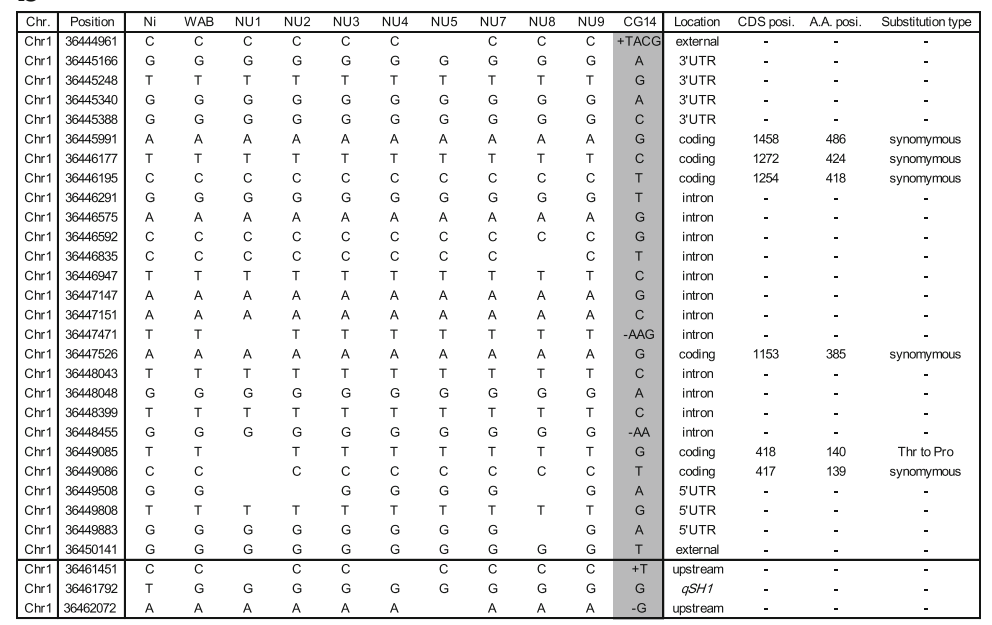

C

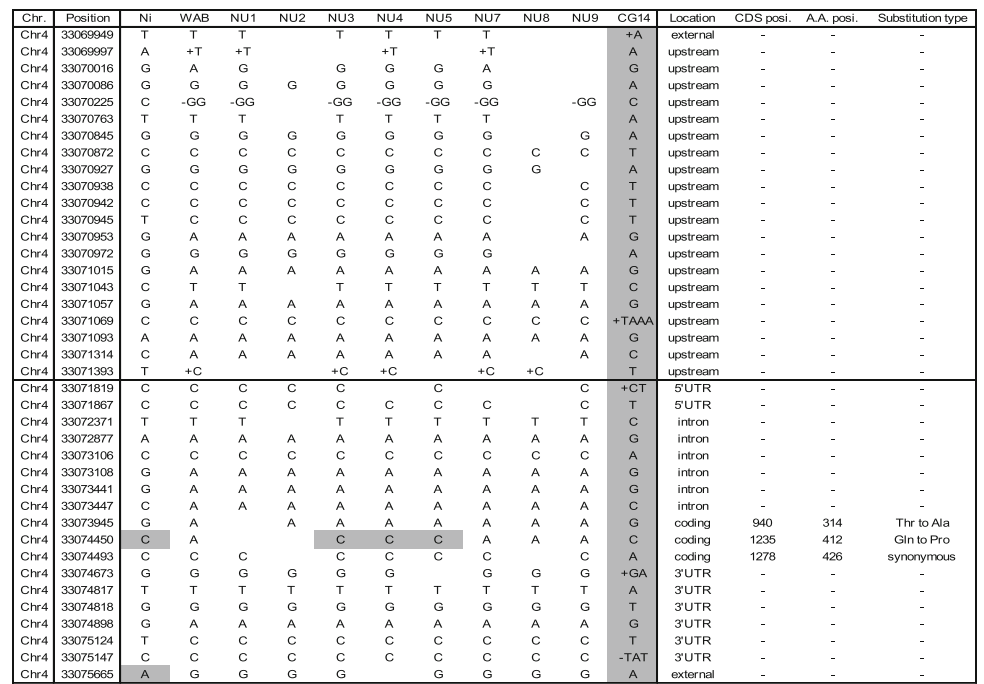


(See figure on previous page.)

Fig. 3 Graphical representation of allelic patterns in the three grain shattering genes. Substitution type indicates amino acids of WAB56-104-allele to CG14-allele. a SHATTERING 3, b qSH1, and c SHAT1. Varietal names are abbreviated as follows: Nipponbare, Ni; WAB56-104, WAB; NERICA 1, NU1; NERICA 2, NU2; NERICA 3, NU3; NERICA 4, NU4; NERICA 5, NU5; NERICA 7, NU7; NERICA 8, NU8; NERICA 9, NU9. CDS posi. and A.A. posi. Represent positions in coding sequences and positions in deduced amino acid sequences, respectively. Alleles of CG14 are colored in gray

possibility of association with trait among the NU varieties and the parental varieties when genes, for which function was determined, showed allelic divergence. For example, Kishine et al. (2008) reported that the allele of granule-bound starch synthase I (GBSSI) from CG14 was associated with high grain amylose content in NU1, 2 and 5.Our graphical genotype indicated association of this gene with the corresponding CG14 introgression segment (Table 5, Additional file 14: Figure S4a). Also, a fragrant rice allele $B A D H 2$, which was found in NU1 (Asante et al. 2010), was located on the three non-parental segments of Chr8: 2037974620,399,750 in NU1 genotype uniquely as expected (Table 5). Ikeda et al. (2009) documented the awnness in NU2 and 5, divergent apiculous color in NU1, 2 and 5, and distinct stigma color in NU1. It appeared that NU2 and 5 conserved CG14 alleles on Regulator of Awn Elongation 1 (RAEI), which is one of genes involved in awn formation in CG14 (Furuta et al. 2015) (Table 5). We noted that $\mathrm{OsC1}$, which is a determinant of anthocyanin accumulation in rice (Chin et al. 2016), was associated with apiculous color among the $8 \mathrm{NU}$ varieties and the parental varieties (Table 5). Although these 'gene-trait relationships' need extensive analyses using other NU varieties or a rice diversity panel, the graphical genotype we have presented can be a starting point and also guides functional validation by molecular genetics.

Gene sequence information of the NU varieties is useful to explore divergent traits and their origin. Here we introduce one example each for biotic and abiotic stress tolerance (Table 5). OsSWEET14 is a susceptibility gene to bacterial leaf blight in wild rice (Hutin et al. 2015). The corresponding locus in the graphical genotype showed that NU1, 2, and 5 had the CG14 alleles (Additional file 14: Figure S4b). Association analysis of those alleles and resistance to bacterial blight may lead to discover differences of NU varieties. Notably, Séré et al. (2005) reported the different susceptibility of NU1 (with
OsSWEET14 from CG14) and NU4 (without OsSWEET14 from CG14).One of salt tolerance determinant gene OsHKT1;5 (Platten et al. 2013), which encodes a $\mathrm{Na}^{+}$transporter, exhibited variation in the NU varieties. Namely, NU3 and NU4 were identical to WAB56-104, but other NU varieties contained non-parental segments in this gene region. This observation is consistent with the concept that salt tolerance in NU4 is derived from WAB56-104 as reported previously (Awala et al. 2010). Interestingly, Yamamoto et al. (2011) reported the similar physiological response of NU3 and NU4 to salt stress compared to other five NU varieties, while NU3 and NU4exhibited different profiles of total amino acids and polyamine. At the same time, Yamamoto et al. (2011) reported salt stress susceptibility of NU2 among the NU varieties. Those differences of NU varieties in salt stress response imply that multiple genetic components for salt stress adaptation are combined differently in their genomes. Platten et al. (2013) reported some O. glaberrima seem to have another salt exclusion mechanism that is independent on OsHKT1;5. Other seven $\mathrm{Na}^{+}$ transporter genes (Platten et al. 2006) exhibited no difference in the chromosomal segments in NU3 and NU4 (Additional file 15: Table S11). Further investigation is required to specify the reason.

\section{Unmapped sequences from WAB 56-104}

More than $10 \%$ of the NU sequences were not mapped correctly on the rice reference genome of Nipponbare. To characterize those sequences, we performed de novo assembly of unmapped reads from WAB56-104. Total of 37,894 genomic scaffolds were constructed; those covered approx. $19 \mathrm{Mb}$ of genomic scaffolds (Additional file 16: Table S12). The smaller value of total nucleotide of the genomics scaffolds than expected would be due to duplication of DNA segments. As evidence, a computational survey predicted 578 of chromosomal regions exhibiting higher copy number variation in WAB56-104 upon the

Table 5 Key genes segregating among the NU varieties

\begin{tabular}{|c|c|c|c|c|c|}
\hline Gene abbreviation & Locus & Trait & Reference & Causal origin & Variety with the gene segmen \\
\hline GBSSI & LOC_Os06g04200 & Grain amylose content & Kishine et al. (2008) & CG14 & NU1, 2, and 5 \\
\hline BADH2 & LOC_Os08g32870 & Grain fragrance & Asante et al. (2010) & WAB638-1 (outcross) & NU1 \\
\hline RAEI & LOC_Os04g28280 & Awnness & Furuta et al. (2015) & CG14 & NU2 and 5 \\
\hline $\mathrm{OsCl}$ & LOC_Os06g10350 & Purple pigment & Chin et al. (2016) & CG14 & NU1, 2, and 5 \\
\hline OSSWEET14 & LOC_Os11g31190 & Bacterial leaf blight susceptibility & Hutin et al. (2015) & CG14 & NU1, 2, and 5 \\
\hline OsHKT1;5 & LOC_Os01g20160 & Salt tolerance & Platten et al. (2013) & WAB56-104 & NU3 and NU4 \\
\hline
\end{tabular}


Table 6 Occurrence of WAB 56-104 specific genes in NU varieties and CG 14

\begin{tabular}{|c|c|c|c|c|c|c|c|c|c|}
\hline \multirow[t]{2}{*}{ Category } & \multirow[t]{2}{*}{ Gene identifier } & \multicolumn{2}{|l|}{ Functional annotation } & \multicolumn{6}{|c|}{ Gene occurrence } \\
\hline & & $\begin{array}{l}\text { Gene of BLAST hit in } \\
\text { Swiss prot }\end{array}$ & $\begin{array}{l}\text { Species of BLAST hit in } \\
\text { Swiss-prot }\end{array}$ & NU3 & NU4 & NU5 & NU7 & CG14 & Remarks \\
\hline \multirow[t]{6}{*}{ Disease } & g13.t1 & $\begin{array}{l}\text { Putative disease resistance } \\
\text { protein } \mathrm{RGA4}\end{array}$ & Solanum bulbocastanum & No & No & No & Yes & No & WAB 56-104 allele \\
\hline & g51.t1 & $\begin{array}{l}\text { Putative disease resistance } \\
\text { RPP13-like protein } 3\end{array}$ & Arabidopsis thaliana & Yes & Yes & Yes & No & No & WAB 56-104 allele \\
\hline & g98.t1 & $\begin{array}{l}\text { Disease resistance protein } \\
\text { RPP13 }\end{array}$ & Arabidopsis thaliana & Yes & Yes & No & Yes & Yes & WAB 56-104 allele \\
\hline & g108.t1 & $\begin{array}{l}\text { Putative disease resistance } \\
\text { RPP13-like protein } 1\end{array}$ & Arabidopsis thaliana & No & No & No & No & Yes & Polymorphic in parents \\
\hline & g342.t1 & Chitin elicitor-binding protein & Oryza sativa & Yes & Yes & No & No & No & WAB 56-104 allele \\
\hline & g632.t1 & $\begin{array}{l}\text { Putative disease resistance } \\
\text { RPP13-like protein } 2\end{array}$ & Arabidopsis thaliana & Yes & Yes & No & Yes & No & WAB 56-104 allele \\
\hline \multirow[t]{5}{*}{ Receptor } & g85.t1 & $\begin{array}{l}\text { Wall-associated receptor } \\
\text { kinase-like } 18\end{array}$ & Arabidopsis thaliana & Yes & Yes & Yes & No & Yes & Both parental allele \\
\hline & g115.t1 & $\begin{array}{l}\text { Wall-associated receptor } \\
\text { kinase-like } 18\end{array}$ & Arabidopsis thaliana & Yes & Yes & Yes & No & Yes & Both parental allele \\
\hline & g227.t1 & $\begin{array}{l}\text { Wall-associated receptor } \\
\text { kinase } 2\end{array}$ & Arabidopsis thaliana & Yes & Yes & No & Yes & No & WAB 56-104 allele \\
\hline & g162.t1 & Receptor-like protein 12 & Arabidopsis thaliana & Yes & Yes & Yes & No & Yes & $\begin{array}{l}\text { WAB 56-104 allele in } \\
\text { NU3 and NU4.CG } 14 \\
\text { allele in NU5. }\end{array}$ \\
\hline & g418.t1 & $\begin{array}{l}\text { G-type lectin S-receptor-like } \\
\text { serine/threonine-protein } \\
\text { kinase LECRK3 }\end{array}$ & Oryza sativa & Yes & Yes & No & No & No & WAB 56-104 allele \\
\hline \multirow[t]{10}{*}{ Others } & g173.t1 & 11-oxo-beta-amyrin 30-oxidase & Glycyrrhiza uralensis & No & No & Yes & No & Yes & Unspecified \\
\hline & g268.t1 & Uncharacterized protein & Arabidopsis thaliana & Yes & Yes & No & Yes & No & $\begin{array}{l}\text { WAB 56-104 allele in } \\
\text { NU3 and NU4. Unspecified } \\
\text { in NU7. }\end{array}$ \\
\hline & g338.t1 & F-box/FBD/LRR-repeat protein & Arabidopsis thaliana & No & No & No & No & Yes & Polymorphic in parents \\
\hline & g361.t1 & Cytochrome P450 87A3 & Oryza sativa & Yes & Yes & No & Yes & No & Both parental allele \\
\hline & g427.t1 & UPF0481 protein & Arabidopsis thaliana & Yes & Yes & No & No & No & WAB 56-104 allele \\
\hline & g453.t1 & Tetraspanin-8 & Arabidopsis thaliana & Yes & Yes & No & No & No & WAB 56-104 allele \\
\hline & g500.t1 & Protein Brevis radix-like 2 & Arabidopsis thaliana & Yes & Yes & Yes & No & Yes & WAB 56-104 allele \\
\hline & g517.t1 & UDP-glycosyltransferase 76E11 & Arabidopsis thaliana & Yes & Yes & Yes & No & Yes & WAB 56-104 allele \\
\hline & g597.t1 & Basic blue protein & Cucumis sativus & Yes & Yes & Yes & No & Yes & WAB 56-104 allele \\
\hline & g643.t1 & $\begin{array}{l}\text { Autonomous transposable } \\
\text { element EN-1 mosaic protein }\end{array}$ & Zea mays & No & No & Yes & No & No & WAB 56-104 allele \\
\hline
\end{tabular}

Nipponbare genome (with E-value of 0.01), and notably, it was more than 460 sites in CG14. Hence, we assumed that some unmapped WAB56-104 sequence reads were mapped on highly related paralogous chromosomal regions in Nipponbare.

Structural annotation of long assembled genomic scaffolds (no less than $1 \mathrm{~kb}$ ) by Augustus (Stanke and Morgenstern 2005) predicted 653 genes. A large part of the predicted gene proteins had homology with cereal proteins (Additional file 16: Table S12 and Additional file 17: Table S13). Notably, 95.6\% (624) did not show strong sequence homology (less than $90 \%$ identity) with Nipponbare proteome sequences (Additional file 17: Table S13). Genes with particular functional annotations showed frequent localization on the scaffolds with statistical significance (in Fisher's exact test at $5 \%$ level); 35 genes for disease resistance protein ( $p$ value $=0), 10$ genes for wall-associated receptor kinase (WAK) ( $p$ value $=0)$, seven genes for leucinerich repeat (LRR) receptor-like serine/threonine-protein kinase $\left(p\right.$ value $\left.=5.6 \mathrm{E}^{-3}\right)$, six genes for lectin receptor kinase $(\mathrm{LRK})(p$ value $=0)$, and five genes for cytochrome P450 $\left(p\right.$ value $\left.=4.4 \mathrm{E}^{-2}\right)$. Potential abiotic stress-related genes (25) were obviously observed prominently. WAKs, LRR receptor-like serine/threonine-protein kinases, LRKs can be involved in pathogen resistance and abiotic stress response (Afzal et al. 2008; Kanneganti and Gupta 2008; 
Vaid et al. 2013). A WAK was implicated as one of the NAM transcription factor regulated genes in drought tolerance (Dixit et al. 2015). Those maternal genes might be the basis for the characteristics in WAB56-104, perhaps for biotic and abiotic stress tolerance. Sakai et al. (2011) observed more frequent distribution of proteins with protein kinase domains, leucine-rich repeat domains, and disease resistance gene on unmapped sequences from $O$. glaberrima.

To analyze whether the maternal genes above exist in the NU genomes or not, we re-mapped unmapped sequence reads of NU3, 4, 5, and 7 upon the genomic scaffolds of unmapped WAB56-104 sequences. The result indicated that 56 genes exhibited segregation among the four NU varieties and CG14 (Additional file 17: Table S13). Fifty one of them were segregated among the four NU varieties. Total of 21 genes were functionally annotated by a BLAST search against the SwissProt database (Table 6). Most of the genes exhibited WAB56-104 allele in NU varieties except two. It is unknown how those genes might contribute on divergent agronomic traits related to biotic and abiotic stress resistance in the NU and parental varieties. Association analysis using DNA markers of those genes may lead to discovery of useful genes in agronomy.

\section{Conclusions}

Interspecific hybrids NU varieties have a great potential for improvement of rice, especially for Africa. Due to the unique breeding processes, the NU genomes required in-depth analyses. The present study provided a draft whole picture of the NU genomes, including polymorphisms, introgression from the donor parent, some potential introgression segments by outcross and de novo mutations.

Currently, short length polymorphisms, especially SNPs have played a central role in rice breeding, genetics, and biology (Feltus et al. 2004). SNP is the ultimate DNA marker which can be detected by several methods such as SNP chip, next generation sequencing, restriction enzymes, and real-time PCR (Kim and Misra, 2007; Varshney et al. 2009). SNP genotyping data are useful for QTL mapping for agronomic traits, genome wide association study, and measurement of genetic distance (Yonemaru et al. 2010; Korte and Farlow 2013). Since SNPs can be relevant in terms of biochemical function of protein and gene regulation, nucleotide substitutions themselves could be causal of particular traits and thus be markers for breeding (Anderssen and Lübberstedt 2003; Gupta and Rustgi 2004). Approx. $81 \%$ of our polymorphic sites were on genic regions, and $43 \%$ were on promoter regions. In the NU varieties, divergence was observed in quantitative agronomic traits and apparent phenotypes (Ikeda et al. 2009; Sanni et al. 2009; Fukuta et al. 2012; Saito et al. 2012; Rodenburg et al. 2015). Studies over the past years have also accumulated data that captures the physiological behavior of the NUs and their divergence in abiotic stress responses (Yamamoto et al. 2011; Atayese et al., 2016; Sikuku et al. 2012; Sakariyawo et al. 2015). In most cases the genetic reasons for divergence in traits are not known. The polymorphism panel resource we created is useful for identification of agronomically useful traits in rice.

In conclusion, our analyses revealed genome characteristics of the NU varieties and the parental varieties. The established whole genome polymorphic resource and knowledge are useful for addressing the genetic reasons of the prominent agronomic characteristics in the NERICA and promotes marker-assisted selection in the development of new rice cultivars. This is especially useful in the light of the critical information about the close relationship between pairs of some NERICA varieties. The genotyping matrix for the $8 \mathrm{NU}$ and the parental lines is available upon request.

\section{Additional files}

Additional file 1: Table S1. Summary of whole genome sequencing
data. (XLSX $12 \mathrm{~kb})$

Additional file 2: Figure $\mathbf{S} 1$. $k$-mer analysis $(k$-merlength $=17)$. The $X$ axis shows $k$-mer depth, and the $Y$-axis shows proportion that represents the frequency at that $k$-mer depth divided by to total frequency of all $k$-mer depth. (a) WAB56-104, (b) CG14, (c) NERICA 3, (d) NERICA 4, (e) NERICA 5, (f) NERICA 7. Arrow indicates a peak of heterogeneous sequences.Peak between 0 to 8 of $k$-mer depth would be due to sequencing error or contaminants. (PPTX $109 \mathrm{~kb}$ )

Additional file 3: Table S2. MNPs between WAB 56-104 and CG 14. (XLSX 9 kb)

Additional file 4: Table S3. Distribution of InDel length. (XLSX 12 kb)

Additional file 5: Table S4. Validation result of parental polymorphic sites. (XLSX $12 \mathrm{~kb}$ )

Additional file 6: Table S5. Public whole genome sequence data in upland NERICA. (XLSX $9 \mathrm{~kb}$ )

Additional file 7: Table S6. Common introgression segments from CG 14. (XLSX 104 kb)

Additional file 8: Table S7. Location of xyloglucan fucosyltransferase genes on common long introgression segments from CG 14. (XLSX 11 kb)

Additional file 9: Figure S2. Phylogeny of genes for fucogalactoxyloglucan biosynthesis. Predicted proteins sequences were aligned by 'CLUSTAL $\Omega$ ' and a phylogenetic dendrogram was constructed by 'Simple Phylogeny' using the neighbor-joining method with the option of 'exclude gaps'. Twelve fucosyltransferase genes in Arabidopsis (AtFUT1 to AtFUT12), four candidate genes for galactosyltransferase in rice, four candidate genes for acetyltransferase genes in rice were analyzed together with the five fucosyltransferase genes with CG14alleles. The five fucosyltransferase genes of interest were marked with a circle. (PPTX $85 \mathrm{~kb}$ )

Additional file 10: Figure S3. Graphical representation of allelic patterns in the two fucosyltransferase. Substitution type indicates amino acids of WAB56-104-allele to CG14-allele. (a) LOC_Os06g10910 and (b) LOC_Os06g10920. Varietal names are abbreviated as follows: Nipponbare, Ni; WAB56-104, WAB; NERICA 1, NU1; NERICA 2, NU2; NERICA 3, NU3; NERICA 4, NU4; NERICA 5, NU5; NERICA 7, NU7; NERICA 8, NU8; NERICA 9, NU9. CDS posi. and A.A. posi. Represent positions in coding sequences 
and positions in deduced amino acid sequences, respectively. Alleles of CG14 are colored in gray. (PPTX $205 \mathrm{~kb}$ )

Additional file 11: Table S8. Variety/lineage-specific introgression segments from CG 14. (XLSX $11 \mathrm{~kb}$ )

Additional file 12: Table S9. Genes on variety/lineage-specific introgression segments from CG 14. (XLSX $1971 \mathrm{~kb})$

Additional file 13: Table S10. Enriched Gene Ontology on the introgression segments from CG 14. (XLSX $20 \mathrm{~kb}$ )

Additional file 14: Figure S4. Graphical genotype of GBSS/ and OsSWEET14 at gene level. Polymorphic position is indicated by vertical line. WAB56-104 segment is presented by while rectangle, and CG14 allele is presented in gray rectangle. Arrow represent the position of gene. (a) GBSSI, (b) OsSWEET14. Representative polymorphic sites were used. (PPTX $76 \mathrm{~kb})$

Additional file 15: Table S11. Allelic patterns of LOC Os01g20160 (OsHKT1;5). (XLSX 28 kb)

Additional file 16: Table S12. Summary of genome assembly and annotation of unmapped reads from WAB 56-104. (XLSX $11 \mathrm{~kb}$ )

Additional file 17: Table S13. Genes on the genome assembly of unmapped sequences from WAB 56-104. (XLSX $180 \mathrm{~kb})$

\section{Abbreviations}

CAPS: Cleaved amplified polymorphic sequences; Fuc: Fucose; GBSSI: Granule-bound starch synthase I; GO: Gene ontology; GOEA: Gene ontology enrichment analysis; InDel: Insertion and deletion; LRK: Lectin receptor kinase; LRR: Leucine-rich repeat; MNP: Multi nucleotide polymorphism; NERICA: New Rice for Africa; NU: Upland New Rice for Africa; PCA: Principal component analysis; PI: Propidium iodide; OTL: Quantitative trait locus; RAE1: Regulator of Awn Elongation 1; SNP: Single nucleotide polymorphism; SSR: Simple sequence repeat; WAK: Wall-associated receptor kinase; WARDA: The West Africa Rice Development Association

\section{Acknowledgements}

We thank Mr. Francisco V. Gulay and Mrs. Maria Elena Escosura for plant material preparation. We also thank Mrs. Blesilda Enriquez for preparation of genomic DNA. We also thank Dr. Kiyoshi Yamada in Faculty of Agriculture in Utsunomiya University for technical assistance of flow cytometry analysis.

\section{Funding}

This study was supported by the 'Rapid Mobilization of Alleles for Rice Cultivar Improvement in Sub-Saharan Africa' project of the Bill and Melinda Gates Foundation Grant Number OPP1080832 to AfricaRice.

\section{Availability of data and materials}

The polymorphism panel of $\mathrm{NU}$ varieties is available upon request. Please contact to n.yamamoto@irri.org and a.kohli@irri.org.

\section{Authors' contributions}

NY created and analyzed the experimental and computational data. RG and CS assisted the experimental and computational procedures. TS arranged flow cytometry measurements and assisted data analysis. YT prepared standard plant materials for flow cytometry analysis and assisted data analysis. RV contributed to the design of this study and plant material preparation. AK conceived the idea of the study, organized inputs from al the authors and finalized the manuscript. All authors read and approved the final manuscript.

\section{Authors' information}

Strategic Innovation Platform, International Rice Research Institute, DAPO 7777, Metro Manila, 1226, Philippines.

Utsunomiya University, 350 Mine-machi, Utsunomiya, Tochigi, Japan. Tokyo University of Technology, 1404-1 Katakura, Hachioji, Tokyo, Japan. Africa Rice Center, 01 BP 4029, Abidjan 01, Côte d'Ivoire.

\section{Ethics approval and consent to participate} Not applicable.

\section{Competing interests}

The authors declare that they have no competing interests.

\section{Publisher's Note}

Springer Nature remains neutral with regard to jurisdictional claims in published maps and institutional affiliations.

\section{Author details}

${ }^{1}$ International Rice Research Institute, Los Baños, Laguna, Philippines.

${ }^{2} U t s u n o m i y a$ University, 350 Mine-machi, Utsunomiya, Tochigi, Japan. ${ }^{3}$ Tokyo University of Technology, 1404-1 Katakura, Hachioji, Tokyo, Japan. ${ }^{4}$ Africa Rice Center, 01 BP 4029, Abidjan 01, Côte d'Ivoire.

Received: 4 November 2017 Accepted: 30 April 2018

Published online: 15 May 2018

\section{References}

Abyzov A, Urban AE, Snyder M, Gerstein M (2011) CNVnator: an approach to discover, genotype, and characterize typical and atypical CNVs from family and population genome sequencing. Genome Res 21:974-984

Africa Rice Center (2008) Africa rice trends 2007. Africa Rice Center, Cotonou, Benin

Afzal AJ, Wood AJ, Lightfoot DA (2008) Plant receptor-like serine threonine kinases: roles in signaling and plant defense. MPMI 21:507-517

Albar L, Ndjiondjop MN, Esshak Z, Berger A, Pinel A, Jones M et al (2003) Fine genetic mapping of a gene required for Rice yellow mottle virus cell-to-cell movement. Theor Appl Genet 107:371-378

Alexandrov N, Tai S, Wang W, Mansueto L, Palis K, Fuentes RR, Ulat VJ, Chebotarov D, Zhang G, Li Z, Mauleon R, Hamilton RS, McNally KL (2015) SNP-seek database of SNPs derived from 3000 rice genomes. Nucleic Acids Res 43:D1023-D1027

Aluko G, Martinez C, Tohme J, Castano C, Bergman C, Oard JH (2004) QTL mapping of grain quality traits from the interspecific cross Oryza sativa $\times 0$. glaberrima. Theor Appl Genet 109:630-639

Andorf CM, Cannon EK, Portwood JLII, Gardiner JM, Harper LC, Schaeffer ML et al (2015) MaizeGDB update: new tools, data and interface for the maize model organism database. Nucleic Acids Res 44:D1195-D1201

Arumuganathan K, Earle ED (1991) Nuclear DNA content of some important plant species. Plant Mol Biol Rep 9:208-218

Asante MD, Kovach MJ, Huang L, Harrington S, Dartey PK, Akromah R et al (2010) The genetic origin of fragrance in NERICA1. Mol Breed 26:419-424

Atayese M, Olagunju S, Sakariyawo O, Oyekanmi A, Babalola O, Aderibigbe S et al (2016) Root response of some selected rice varieties to soil moisture stress at different phenological stages. Journal of agricultural science and. Environment 12:93-113

Attere AF, Fatokun CA (1983) Reaction of Oryzaglaberrima accessions to rice yellow mottle virus. Plant Dis 67:420-421

Awala SK, Nanhapo I, Sakagami Jl, Kanyomeka L, lijima M (2010) Differential salinity tolerance among Oryza glaberrima, Oryza sativa and their interspecies including NERICA. Plant Prod Sci 13:3-10

Baack EJ, Rieseberg LH (2007) A genomic view of introgression and hybrid speciation. Curr Opin Genet Dev 17:513-518

Bennett MD, Leitch IJ (2005) Nuclear DNA amounts in angiosperms: progress, problems and prospects. Ann Bot 95:45-90

Bennett MD, Leitch IJ, Price HJ, Johnston JS (2003) Comparisons with Caenorhabditis (approximately $100 \mathrm{Mb}$ ) and drosophila (approximately $175 \mathrm{Mb}$ ) using flow cytometry show genome size in Arabidopsis to be approximately 157 $\mathrm{Mb}$ and thus approximately 25\% larger than the Arabidopsis genome initiative estimate of approximately $125 \mathrm{Mb}$. Ann Bot 91:547-557

Boeckmann B, Blatter MC, Famiglietti L, Hinz U, Lane L, Roechert B, Bairoch A (2005) Protein variety and functional diversity: Swiss-Prot annotation in its biological context. C R Biol 328:882-999

Bolger AM, Lohse M, Usadel B (2014) Trimmomatic: a flexible trimmer for Illumina sequence data. Bioinformatics 30:2114-2120

Burr B (2002) Mapping and sequencing the rice genome. Plant Cell 14:521-523

Chen X, Schulz-Trieglaff O, Shaw R, Barnes B, Schlesinger F, Källberg M, Cox A, Kruglyak S, Saunders CT (2016) Manta: rapid detection of structural variants and indels for germline and cancer sequencing applications. Bioinformatics 32:1220-1222

Chin HS, Wu YP, HourAL HCY, Lin YR (2016) Genetic and evolutionary analysis of purple leaf sheath in Rice. Rice 9:8 
Conesa A, Götz S $(2008,2008)$ Blast2GO: a comprehensive suite for functional analysis in plant genomics. Int J Plant Genomics:619832

Deorowicz S, Kokot M, Grabowski S, Debudaj-Grabysz A (2015) KMC 2: fast and resource-frugal k-mer counting. Bioinformatics 31:1569-1576

Dixit S, Biswal AK, Min A, Henry A, Oane RH, Raorane ML, Longkumer T, Pabuayon IM, Mutte SK, Vardarajan AR, Miro B, Govindan G, Albano-Enriquez B, Pueffeld M, Sreenivasulu N, Slamet-Loedin I, Sundarvelpandian K, Tsai Y-C, Raghuvanshi S, Hsing Y-IC, Kumar A, Kohli A (2015) Action of multiple intraQTL genes concerted around a co-localized transcription factor underpins a large effect QTL. Scientific Reports 5(1)

Doležel J, BartoŠ J, Voglmayr H, Greilhuber J (2003) Nuclear DNA content and genome size of trout and human. Cytometry A 51:127-128

Doyle JJ (1987) A rapid DNA isolation procedure for small quantities of fresh leaf tissue. Phytochem Bull 19:11-15

Duvick J, Fu A, Muppirala U, Sabharwal M, Wilkerson MD, Lawrence CJ et al (2008) PlantGDB: a resource for comparative plant genomics. Nucleic Acids Res 36:D959-D965

Feltus FA, Wan J, Schulze SR, Estill JC, Jiang N, Paterson AH (2004) An SNP resource for rice genetics and breeding based on subspecies indica and japonica genome alignments. Genome Res 14:1812-1819

Food and Agriculture Organization of the United Nations (FAO) (2013a) FAOSAT online statistical service. FAO, Rome

Food and Agriculture Organization of the United Nations (FAO) (2013b) Yearbook, FAO statistical. "World food and agriculture". FAO, Rome

Fukuta Y, Konisho K, Senoo-Namai S, Yanagihara S, Tsunematsu H, Fukuo A, Kumashiro T (2012) Genetic characterization of rainfed upland new Rice for Africa (NERICA) varieties. Breed Sci 62:27-37

Furuta T, Komeda N, Asano K, Uehara K, Gamuyao R, Angeles-Shim RB et al (2015) Convergent loss of awn in two cultivated rice species Oryza sativa and Oryza glaberrima is caused by mutations in different loci. G3 5:2267-2274

Gupta PK, Rustgi S (2004) Molecular markers from the transcribed/expressed region of the genome in higher plants. Funct Integr Genomic 4:139-162

Haefele SM, Johnson DE, M'Bodj D, Wopereis MCS, Miezan KM (2004) Field screening of diverse rice genotypes for weed competitiveness in irrigated lowland ecosystems. Field Crops Res 88:39-56

Hurwitz BL, Kudrna D, Yu Y, Sebastian A, Zuccolo A, Jackson SA et al (2010) Rice structural variation: a comparative analysis of structural variation between rice and three of its closest relatives in the genus Oryza. Plant J 63:990-1003

Hutin M, Sabot F, Ghesquière A, Koebnik R, Szurek B (2015) A knowledge-based molecular screen uncovers a broad-spectrum OsSWEET14 resistance allele to bacterial blight from wild rice. Plant J 84:694-703

Ikeda R, Sokei Y, Akintayo I (2009) Seed fertility of F1 hybrids between upland rice NERICA cultivars and Oryza sativa L. or O. glaberrima Steud. Breed Sci 59:27-35

Jones MP, Dingkuhn M, Aluko GK, Semon M (1997) Interspecific Oryza sativa L. X O. glaberrimaSteud. Progenies in upland rice improvement. Euphytica 94: 237-246

Kanneganti V, Gupta AK (2008) Wall associated kinases from plants-an overview. Physiol Mol Biol Plants 14:109-118

Kawahara Y, de la Bastide M, Hamilton JP, Kanamori H, McCombie WR, Ouyang S et al (2013) Improvement of the Oryza sativa Nipponbare reference genome using next generation sequence and optical map data. Rice 6:4

Keller O, Kollmar M, Stanke M, Waack S (2011) A novel hybrid gene prediction method employing protein multiple sequence alignments. Bioinformatics 27 757-763

Kim S, Misra A (2007) SNP genotyping: technologies and biomedical applications. Annu Rev Biomed Eng 9:289-320

Kishine M, Suzuki K, Nakamura S, Ohtsubo KI (2008) Grain qualities and their genetic derivation of 7 new rice for Africa (NERICA) varieties. JAgric. Food Chem 56:4605-4610

Konishi S, Izawa T, Lin SY, Ebana K, Fukuta Y, Sasaki T, Yano M (2006) An SNP caused loss of seed shattering during rice domestication. Science 312:1392-1396

Korte A, Farlow A (2013) The advantages and limitations of trait analysis with GWAS: a review. Plant Methods 9:1

Lamesch P, Berardini TZ, Li D, Swarbreck D, Wilks C, Sasidharan R et al (2012) The Arabidopsis information resource (TAIR): improved gene annotation and new tools. Nucleic Acids Res 40:D1202-D1210

Li C, Zhou A, Sang T (2006) Rice domestication by reducing shattering. Science 311:1936-1939

Li H, Durbin R (2009) Fast and accurate short read alignment with burrowswheeler transform. Bioinformatics 25:1754-1760
Li H, Handsaker B, Wysoker A, Fennell T, Ruan J, Homer N, Durbin R (2009) The sequence alignment/map format and SAMtools. Bioinformatics 25:2078-2079

Li JY, Wang J, Zeigler RS (2014) The 3,000 rice genomes project: new opportunities and challenges for future rice research. Gigascience 3:1

Liu B, Shi Y, Yuan J, Hu X, Zhang H, Li N, Li Z, Chen Y, Mu D, Fan W (2013) Estimation of genomic characteristics by analyzing $k$-mer frequency in de novo genome projects eprint arXiv:13082012

Liu L, Paulitz J, Pauly M (2015) The presence of fucogalactoxyloglucan and its synthesis in rice indicates conserved functional importance in plants. Plant Physiol 168:549-560

Lorieux M, Ndjiondjop MN, Ghesquière A (2000) A first interspecific Oryza sativa X Oryza glaberrima microsatellite-based genetic linkage map. Theor Appl Genet 100:593-601

Lorieux M, Reversat G, Diaz SG, Denance C, Jouvenet N, Orieux Y et al (2003) Linkage mapping of $\mathrm{Hsa}-1 \mathrm{Og}$, a resistance gene of African rice to the cyst nematode, Heteroderasacchari. Theor Appl Genet 107:691-696

Luo R, Liu B, Xie Y, Li Z, Huang W, Yuan J et al (2012) SOAPdenovo2: an empirically improved memory-efficient short-read de novo assembler. Gigascience 1:18

Majerus V, Bertin P, Lutts S (2007) Effects of iron toxicity on osmotic potential, osmolytes and polyamines concentrations in the African rice (Oryza glaberrima Steud.). Plant Sci 173:96-105

Martínez CP, Arumuganathan K, Kikuchi H, Earle ED (1994) Nuclear DNA content of ten rice species as determined by flow cytometry. Jpn J Genet 69:513-523

McKenna A, Hanna M, Banks E, Sivachenko A, Cibulskis K, Kernytsky A, DePristo MA (2010) The genome analysis toolkit: a MapReduce framework for analyzing next-generation DNA sequencing data. Genome Res 20:1297-1303

Miyabayashi T, Nonomura Kl, Morishima H, Kurata N (2007) Genome size of twenty wild species of Oryza determined by flow cytometric and chromosome analyses. Breed Sci 57:73-78

Morales $L$ andDujon B (2012) Evolutionary role of interspecies hybridization and genetic exchanges in yeasts. MMBR 76:721-739

Murashige T, Skoog F (1962) A revised medium for rapid growth and bio assays with tobacco tissue cultures. Physiol Plant 15:473-497

Pariasca-Tanaka J, Lorieux M, He C, McCouch S, Thomson MJ, Wissuwa M (2015) Development of a SNP genotyping panel for detecting polymorphisms in Oryza glaberrima/O. sativa interspecific crosses. Euphytica 201:67-78

Paul CP, Ng NQ, Ladeinde TA (2003) Mode of gene action of inheritance for resistance to rice yellow mottle virus. Afr Crop Sci J 11:143-150

Platten JD, Cotsaftis O, Berthomieu P, Bohnert H, Davenport RJ, Fairbairn DJ et al (2006) Nomenclature for HKT transporters, key determinants of plant salinity tolerance. Trends Plant Sci 11:372-374

Platten JD, Egdane JA, Ismail AM (2013) Salinity tolerance, $\mathrm{Na}^{+}$exclusion and allele mining of HKT1; 5 in Oryza sativa and O. glaberrima: many sources, many genes, one mechanism? BMC Plant Biol 13:32

Rieseberg LH, Willis JH (2007) Plant speciation. Science 317:910-914

Rodenburg J, Cissoko M, Kayeke J, Dieng I, Khan ZR, Midega CA et al (2015) Do NERICA rice cultivars express resistance to Striga hermonthica (Del.) Benth. andStriga asiatica (L.) Kuntze under field conditions? Field Crops Res 170:83-94

Saito K, Sokei Y, Wopereis MCS (2012) Enhancing rice productivity in West Africa through genetic improvement. Crop Sci 52:484-493

Sakai H, Ikawa H, Tanaka T, Numa H, Minami H, Fujisawa M, Shibata M, Kurita K, Kikuta A, Hamada M, Kanamori H, Namiki N, Wu J, Itoh T, Matsumoto T, Sasaki T (2011) Distinct evolutionary patterns of Oryza glaberrima deciphered by genome sequencing and comparative analysis. Plant J 66:796-805

Sakariyawo OS, Olagunju SO, Atayese MO, Okeleye KA, PAS S, Aderibigbe SG et al (2015) Physiological and yield response of some upland rice varieties to rewatering after imposed soil moisture stress. J Agric Sci \& Env 15:93-111

Sanni KA, Ojo DK, Adebisi MA, Somado EA, Ariyo OJ, Sie M et al (2009) Ratooning potential of interspecific NERICA rice varieties (Oryza glaberrimax Oryza sativa). Int J Bot 5:112-115

Sano $Y$ (1990) The genic nature of gamete eliminator in rice. Genetics 125:183-191

Sano Y, Sano R, Morishima H (1984) Neighbour effects between two co-occurring rice species, Oryza sativa and O. glaberrima. J Appl Ecol 21:245-254

Sarla N, andSwamy BM (2005) Oryza glaberrima: a source for the improvement of Oryza sativa. Curr Sci:955-963

Sarria R, Wagner TA, O'Neill MA, Faik A, Wilkerson CG, Keegstra K, Raikhel NV (2001) Characterization of a family of Arabidopsis genes related to xyloglucan fucosyltransferase1. Plant Physiol 127:1595-1606

Schatz MC, Maron LG, Stein JC, Wences AH, Gurtowski J, Biggers E et al (2014) Whole genome de novo assemblies of three divergent strains of rice, Oryza sativa, document novel gene space of aus and indica. Genome Biol 15:506 
Semagn K, Ndjiondjop MN, Lorieux M, Cissoko M, Jones M, McCouch S (2007) Molecular profiling of an interspecific rice population derived from a cross between WAB56-104 (Oryza sativa) and CG14 (Oryzaglaberrima). Afr J Biotechnol 6:2014-2022

Semon M, Nielsen R, Jones MP, McCouch SR (2005) The population structure of African cultivated rice Oryza glaberrima (Steud.): evidence for elevated levels of linkage disequilibrium caused by admixture with $O$. sativa and ecological adaptation. Genetics 169:1639-1647

Séré Y, Onasanya A, Verdier V, Akator K, Ouedraogo LS, Segda Z, Coulibaly MM, Sido AY, Basso A (2005) Rice bacterial leaf blight in West Africa: preliminary studies on disease in farmers' fields and screening released varieties for resistance to the bacteria. Asian J Plant Sci 4:577-579

Sié M, Sanni K, Futakuchi K, Manneh B, Mandé S, Vodouhé R, Dogbe S, Dramé KN, Ogunbayo A, Ndjiondjop MN, Traoré K (2012) Towards a rational use of African rice (OryzaglaberrimaSteud.) for breeding in sub-Saharan Africa. G3 (6):1-7

Sikuku PA, Onyango JC, Netondo GW (2012) Physiological and biochemical responses of five nerica rice varieties (Oryza sativa L.) to water deficit at vegetative and reproductive stage. Agric Biol J North Am 3:93-104

Singh RK, Sharma RK, Singh AK, Singh VP, Singh NK, Tiwari SP, Mohapatra T (2004) Suitability of mapped sequence tagged microsatellite site markers for establishing distinctness, uniformity and stability in aromatic rice. Euphytica 135:135-143

Somado EA, Guei RG, Keya SO (2008) NERICA: the new rice for Africa-a compendium: 2008 edition. Africa Rice Center (WARDA), Cononou, Benin.

Stanke M, Morgenstern B (2005) AUGUSTUS: a web server for gene prediction in eukaryotes that allows user-defined constraints. Nucleic Acids Res 33:W465-W467

Tian T, Liu Y, Yan H, You Q, Yi X, Du Z, Xu W, Su Z (2017) agriGO v2.0: a GO analysis toolkit for the agricultural community, 2017 update. Nucleic Acids Res 45(W1):W122-W129. https://doi.org/10.1093/nar/gkx382.

Traore K, McClung AM, Fjellstrom R, Futakuchi K (2011) Diversity in grain physicochemical characteristics of west African rice, including NERICA genotypes, as compared to cultivars from the United States of America. IRJAS 1:435-448

Uozu S, Ikehashi H, Ohido N, Ohtsubo H, Ohtsubo E, Fukui K (1997) Repetitive sequences: cause for variation in genome size and chromosome morphology in the genus Oryza. Plant Mol Biol 35:791-799

Vaid N, Macovei A, Tuteja N (2013) Knights in action: lectin receptor-like kinases in plant development and stress responses. Mol Plant 6:1405-1418

Varshney RK, Nayak SN, May GD, Jackson SA (2009) Next-generation sequencing technologies and their implications for crop genetics and breeding. Trends Biotechnol 27:522-530

Vikal Y, Das A, Patra B, Goel RK, Sidhu JS, Singh K (2007) Identification of new sources of bacterial blight (Xanthomonas oryzae pv. Oryzae) resistance in wild Oryza species and O. glaberrima. Plant Genet Resour 5:108-112

Wang M, Yu Y, Haberer G, Marri PR, Fan C, Goicoechea JL et al (2014) The genome sequence of African rice (Oryza glaberrima) and evidence for independent domestication. Nat Genet 46:982-988

Yamamoto A, Sawada H, Shim IS, Usui K, Fujihara S (2011) Effect of salt stress on physiological response and leaf polyamine content in NERICA rice seedlings. Plant Soil Environ 57:571-576

Yonemaru Jl, Yamamoto T, Fukuoka S, Uga Y, Hori K, Yano M (2010) Q-TARO: QTL annotation rice online database. Rice 3:194-203

Zabotina OA (2012) Xyloglucan and its biosynthesis. Front Plant Sci 3:134

Zhou Y, Lu D, Li C, Luo J, Zhu BF, Zhu J et al (2012) Genetic control of seed SHATTERING in rice by the APETALA2 transcription factor SHATTERING ABORTION1. Plant Cell 24:1034-1048

\section{Submit your manuscript to a SpringerOpen ${ }^{\circ}$ journal and benefit from:}

- Convenient online submission

- Rigorous peer review

Open access: articles freely available online

- High visibility within the field

- Retaining the copyright to your article

Submit your next manuscript at $>$ springeropen.com 